\title{
BMJ Open Economic evaluation of an Australian nurse home visiting programme: a randomised trial at 3 years
}

Shalika Bohingamu Mudiyanselage (D) , ${ }^{1}$ Anna M H Price (D) , 2,3,4

Fiona K Mensah (1) ,", Hannah E Bryson (1) ,2,3 Susan Perlen (1) ,2,3 Francesca Orsini (D) , ${ }^{5,6}$ Harriet Hiscock (D) , ${ }^{3}$ Penelope Dakin, ${ }^{7}$ Diana Harris (D) , Kristy Noble, ${ }^{7}$ Tracey Bruce (1) , ${ }^{8}$ Lynn Kemp, ${ }^{8}$ Sharon Goldfeld (1) , 2,3,4 Lisa Gold (1) ${ }^{1}$

To cite: Bohingamu Mudiyanselage S, Price AMH, Mensah FK, et al. Economic evaluation of an Australian nurse home visiting programme: a randomised trial at 3 years. BMJ Open 2021;11:e052156. doi:10.1136/ bmjopen-2021-052156

- Prepublication history and additional supplemental material for this paper are available online. To view these files, please visit the journal online (http://dx.doi.org/10.1136/ bmjopen-2021-052156)

$S G$ and $L G$ are joint senior authors.

Received 07 April 2021 Accepted 14 October 2021

D Check for updates

(c) Author(s) (or their employer(s)) 2021. Re-use permitted under CC BY-NC. No commercial re-use. See rights and permissions. Published by BMJ.

For numbered affiliations see end of article.

Correspondence to Ms Shalika Bohingamu Mudiyanselage; shalika.b@deakin.edu.au

\section{ABSTRACT}

Objectives To investigate the additional programme cost and cost-effectiveness of 'right@home' Nurse Home Visiting (NHV) programme in relation to improving maternal and child outcomes at child age 3 years compared with usual care.

Design A cost-utility analysis from a government-aspayer perspective alongside a randomised trial of NHV over 3-year period. Costs and quality-adjusted lifeyears (QALYS) were discounted at $5 \%$. Analysis used an intention-to-treat approach with multiple imputation. Setting The right@home was implemented from 2013 in Victoria and Tasmania states of Australia, as a primary care service for pregnant women, delivered until child age 2 years.

Participants 722 pregnant Australian women experiencing adversity received NHV $(n=363)$ or usual care (clinic visits) ( $n=359)$.

Primary and secondary outcome measures First, a cost-consequences analysis to compare the additional costs of NHV over usual care, accounting for any reduced costs of service use, and impacts on all maternal and child outcomes assessed at 3 years. Second, cost-utility analysis from a government-as-payer perspective compared additional costs to maternal QALYs to express cost-effectiveness in terms of additional cost per additional QALY gained.

Results When compared with usual care at child age 3 years, the right@home intervention cost \$A7685 extra per woman (95\% CI \$A7006 to \$A8364) and generated 0.01 more QALYs $(95 \% \mathrm{Cl}-0.01$ to 0.02$)$. The probability of right@home being cost-effective by child age 3 years is less than $20 \%$, at a willingness-to-pay threshold of \$A50000 per QALY.

Conclusions Benefits of NHV to parenting at 2 years and maternal health and well-being at 3 years translate into marginal maternal QALY gains. Like previous costeffectiveness results for NHV programmes, right@home is not cost-effective at 3 years. Given the relatively high up-front costs of NHV, long-term follow-up is needed to assess the accrual of health and economic benefits over time.

Trial registration number ISRCTN89962120.
Strengths and limitations of this study

- A randomised controlled trial setting, with regular follow-up and good retention over time for this disadvantaged population.

- Integration of a multiattribute utility instrument and detailed resource use items into trial data collection enables comprehensive assessment of costs and quality-adjusted life-year impact.

- Longer-term follow-up will be required to assess whether emerging benefits over time, as seen in similar programmes in the USA, recoup the large upfront cost.

\section{INTRODUCTION}

Nurse Home Visiting (NHV) programmes have been implemented in many highincome countries to improve the health and quality of life of mothers and their children. ${ }^{1}$ As one of the few early interventions that have been shown to effectively reduce inequitable outcomes for families experiencing socioeconomic and psychosocial adversity, they have substantial policy appeal. ${ }^{2}$ Previous NHV $^{3}$ programmes have varied in their theory, content and targeted population. ${ }^{4-8}$ Most experimental evidence comes from the USA. ${ }^{9}$ In particular, the Nurse Family Partnership (NFP) has shown improvement in the parental care and material life course of high risk women in the USA, ${ }^{10}$ although similar benefits have been variable when translating this programme to other countries. ${ }^{4-8}$

NHV programmes are expensive, mostly due to providing additional professional services in-home at the family/individual level. ${ }^{10}$ In this context opportunities to implement these programmes are challenging with policy-makers requiring rigorous evidence of effectiveness and cost-effectiveness. ${ }^{11}$ Economic evaluations of NHV programmes 
are important to highlight how initial programme implementation costs weigh up against benefits and potential reduced service costs over time. Economic evaluations of NFP have found high upfront programme costs (US\$12265 per family in 2018 US\$) ${ }^{12}$ with benefits that accrue to participants and taxpayers over the child's lifetime, to produce positive returns on investment by child age 30 years. ${ }^{12}{ }^{13}$ However, the evidence for costeffectiveness of NHV programmes in countries with universal healthcare remains unclear or limited.

From 2013, we trialled an NHV programme (right@ home) for pregnant women experiencing psychosocial and socioeconomic adversity in Australia. ${ }^{14}$ The programme was embedded into the universal child and family health $(\mathrm{CFH})$ service, which also provided the comparator. The Australian universal CFH service provides nurse visits at key stages of child's health, learning and development. For example, in Victoria families receive $\mathrm{CFH}$ nurse visits following the hospital discharge (home visit) and, at 2 weeks, 4 weeks, 8 weeks, 4 months, 8 months, 1 year, 18 months, 2 years and 3.5 years at a local CFH clinic. ${ }^{15}$ By the time the right@home NHV programme was completed at child age 2 years, it had led to improved parenting and home environment outcomes over and above the usual service. ${ }^{14}$ Consistent with the NHV literature, it is anticipated that these short-term benefits will generate longer-term benefits to maternal and child health and development, potentially with associated reductions in government services. ${ }^{12} 13$ The aim of this economic evaluation is to analyse the costeffectiveness of the right@home programme to improve maternal and child outcomes 1 year after programme delivery ended. Given the short (12-month) follow-up in the context of the NHV evidence base, ${ }^{10} 1213$ we did not expect the right@home programme to be costeffective by child age 3 years. Rather, we aimed to assess whether upfront programme costs were offset by any early maternal and child outcomes, as an indication that the NHV programme could achieve longer-term positive returns like those seen in the USA.

\section{METHODS}

\section{Design and analytic overview}

The study design is an economic evaluation alongside a randomised controlled trial (RCT) of NHV compared with the usual CFH service. The evaluation considered pregnancy to child age 3 years and comprised two steps.

First, a cost-consequences analysis from a governmentas-payer perspective compared the additional costs of NHV over usual care, accounting for any reduced costs of service use, and impacts on the maternal and child outcomes assessed at 3 years. This multicriteria economic evaluation format incorporates all outcomes judged important in the trial, but results cannot be clearly interpreted as cost-effective or not. ${ }^{16}$

Second, cost-utility analysis from a government-aspayer perspective compared additional costs to maternal quality-adjusted life-years (QALYs). This expresses cost-effectiveness in terms of additional cost per additional QALY gained, which can be interpreted against common Australian benchmarks, whereby programmes with a cost-per-QALY of under $\$ A 50000$ are judged to be cost-effective. ${ }^{17}$

\section{Participants and procedures}

The right@home RCT was implemented from 2013 in two states of Australia, Victoria and Tasmania, in accordance with Consolidated Standards of Reporting Trials requirements. ${ }^{1418}$ Detailed methods are published elsewhere. ${ }^{14}$ Briefly, researchers recruited 722 pregnant, English-speaking women, prioritised for their experience of adversity (at least two of: young pregnancy; not living with another adult; no support in pregnancy; poor health; a long-term illness, health problem or disability that limits daily activities; currently smokes; stress, anxiety or difficulty coping; low education; no person in the household currently earning an income; and never having had a job before) who attended antenatal clinics at 10 public maternity hospitals from 30 April 2013 to 29 August 2014. ${ }^{14} 18$ Participants enrolled by providing informed consent and completing a baseline interview. Participants randomised to the intervention (the right@ home NHV programme, $n=363$ ) were offered a schedule of 25 home visits (60-90 min each) from pregnancy to child age 2 years instead of the usual $8 \mathrm{CFH}$ visits. The NHV programme was delivered by a right@home-trained nurse recruited from the usual CFH service, and one or more visits from right@home-trained social care practitioners who provided psychosocial support for the families: brief counselling, assisting families with housing, service access and financial issues (one dedicated social care practitioner per site, per 100 families $)^{3}$ Participants allocated to usual care $(\mathrm{n}=359)$ received the universal CFH service, which included 6 (Tasmania) or 9 (Victoria) mainly office-based consultations to child age 2 years. When the NHV intervention finished at 2 years, $\mathrm{N}=558$ families enrolled in extended follow-up to 6 years.

\section{Outcome measures}

At the original endpoint of 2 years, the primary outcomes were multiple measures of parenting and the home environment; half showed small-to-moderate effect sizes (ES) in favour of the intervention and none favoured usual care. ${ }^{18}$ At 3 years, outcomes included multiple maternal health and well-being and child health and learning outcomes (see online supplemental table 1). For this paper, the Assessment of Quality of Life (AQoL-8D) ${ }^{19}$ was used to capture mothers' health-related quality of life at four time-points (baseline and child ages 1, 2, 3 years); we used the health-related utility score to calculate QALYs. ${ }^{19}$ QALYs were calculated as linear interpolation using AQoL data at time points $\mathrm{x}$ and $(\mathrm{x}+1)$. Data were complete at baseline; where data were missing at later time points, QALYs were interpolated over a maximum 
Table 1 Unit cost of health resources



CFHS, Child and Family Health Services.

of 2 years (from $\mathrm{x}$ to $(\mathrm{x}+2))$. We did not estimate QALYs for children.

\section{Economic evaluation}

Costs are based on the health resources used by the woman and her child from recruitment to child age 3 years. Data on birth hospital admission and NHV/CFH service use (including the number and type, eg, home/ clinic/phone) were extracted from service records. Other health resources including hospital admissions and community-based services were self-reported by women in interviews conducted by phone (at child ages 6 weeks, and 6, 18 and 30 months) and face-to-face (at baseline and child ages 1, 2 and 3 years). Participants were asked to recall service use since the last questionnaire for hospital admissions (inpatient, outpatient and emergency visits) and community-based services (eg, general practice and specialist physician visits, breastfeeding/ lactation consultations, use of helplines, pharmacy, physiotherapy). Unit costs for each item of service use were sourced from national-level estimates where possible (table 1). All costs are presented in 2016/2017 Australian dollars. Implementation costs of $\mathrm{NHV} / \mathrm{CFH}$ included nurse/practitioner visits, training, supervision and overheads. Nurses in both trial arms had similar qualifications (registered midwife/nurse with additional qualifications in maternal and child health). ${ }^{14}$ Unit costs of CFH nurse visits were confirmed with providers and included travel time and costs, standard materials and overheads (\$A330 per home visit, \$A110 per clinic visit). Costs for the additional online and face-to-face training received by right@ home (intervention) nurses included trainer and nurse time, venue hire, catering, materials and travel. These training costs were distributed over an assumed 5-year caseload of 60 women to avoid artificially overloading training costs onto the restricted number of RCT participants. The right@home programme was associated with slightly higher supervision load than usual CFH service care, additional social worker time and parent materials 


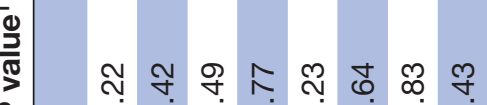

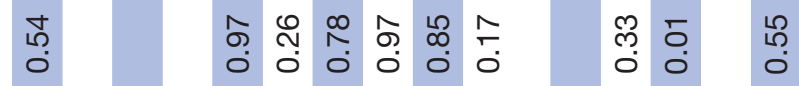

गิ

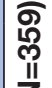

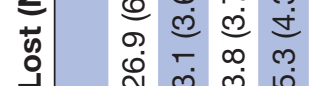

$0-\infty$

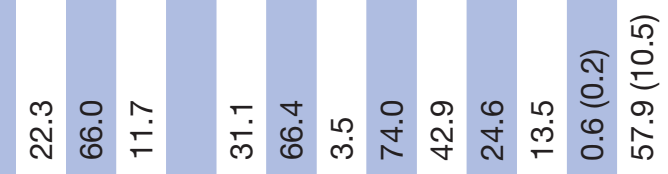

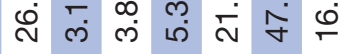

ֻُ

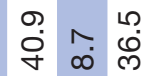

ชै ซิ

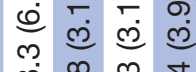

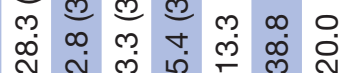

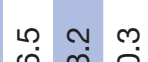

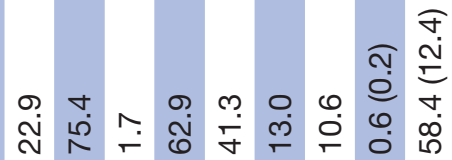

응

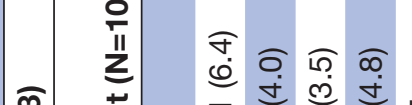

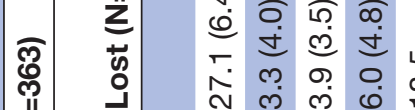

ก.

กิ

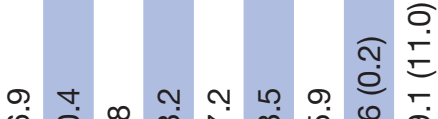

ลิ

m

ஸे

$\begin{array}{ll}m & 0 \\ \dot{m} & 0\end{array}$

ஸ̃

कุ

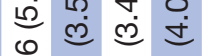

c.

$\left(\frac{10}{2}\right.$

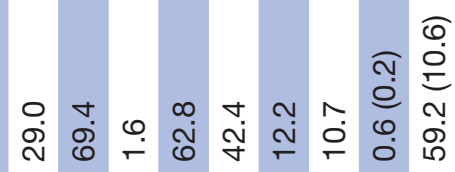

$\begin{array}{ll}0 & \infty \\ \text { ले } & \stackrel{1}{+}\end{array}$

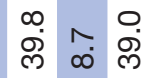

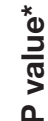

ூூ

กั่

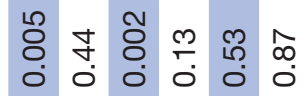

$\begin{array}{lll}0 & 0 \\ \infty & 0 & \hat{N} \\ 0 & 0 & 0\end{array}$

ヘิ

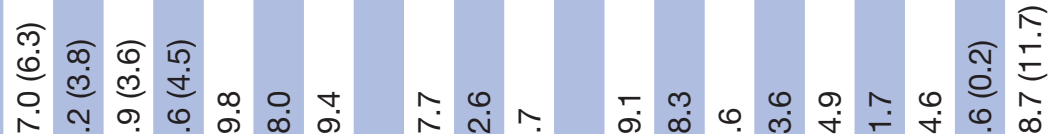

สุ ต ต อ

๑ ले लें

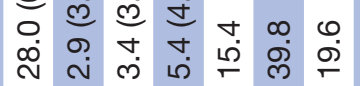

๗ं

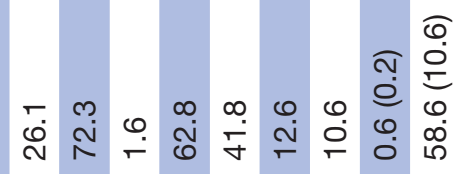


costs. ${ }^{20}$ These 'additional intervention costs' are accrued per-nurse and allocated top-down to each participant.

Patient and public involvement

There was no patient and public involvement in the development or analysis of the study

\section{Analyses}

Methods to address missing data: Characteristics of women who participated vs those lost to follow-up at 3 years were compared using t tests for continuous and $\chi^{2}$ tests for categorical data. For the total health service cost and its subcategories (hospital clinics, hospital admissions and primary health services), maternal and child outcomes, and QALY analyses, multiple imputation was used to account for lost to follow-up and missing data. Multiple imputation was conducted using multivariate normal regression within each of the two treatment groups to allow for differing mechanisms by which missing data may have arisen across the groups. Imputation models included all outcomes collected at 3 years, stratification factors and baseline covariates; 30 data sets were imputed. The health service use and intervention cost variables were not imputed because the high levels of missing data and collinearity prevented robust imputation; complete case data are presented for analyses involving these variables.

All comparisons are reported as mean differences (MDs) and OR, with 95\% CIs obtained using linear regression and logistic regression models, respectively, adjusted for baseline characteristics of, child sex, family's Socio-Economic Index For Area (SEIFA) score, maternal education, maternal age at child's birth, parity, antenatal risk, maternal self-efficacy and maternal mental health; plus child age at the 3-year assessment. Results in the tables are reported MDs, standardised ES or ORs with 95\% CI. To make comparisons of intervention effect comparable between outcomes, standardised ES were obtained by running the linear regression described above on Z-scores calculated on each of the continuous outcomes.

Between-group analyses of health service use were grouped into hospital outpatient clinics, hospital (inpatient) admissions and primary health services, presented as the cost of service use per year. As cost data relate to the use of resources over 3 years, costs after the first year are discounted at $5 \%$ (the rate required by Australian guidelines) $)^{21}$ to present costs in net present value terms. ${ }^{22}$ In economic evaluation, QALYs over 3 years are similarly discounted. All regression analyses accounted for effects of nurse clustering. ${ }^{14} 18$

The incremental cost-effectiveness ratio (ICER) was calculated as the MD in costs between intervention and usual care groups at 3 years divided by the MD in QALYs between groups at 3 years. ${ }^{23}$ This presents the extra cost for each additional QALY gained. Uncertainty was illustrated using a cost effectiveness plane showing 95\% CIs around the ICER generated using the bootstrap method 


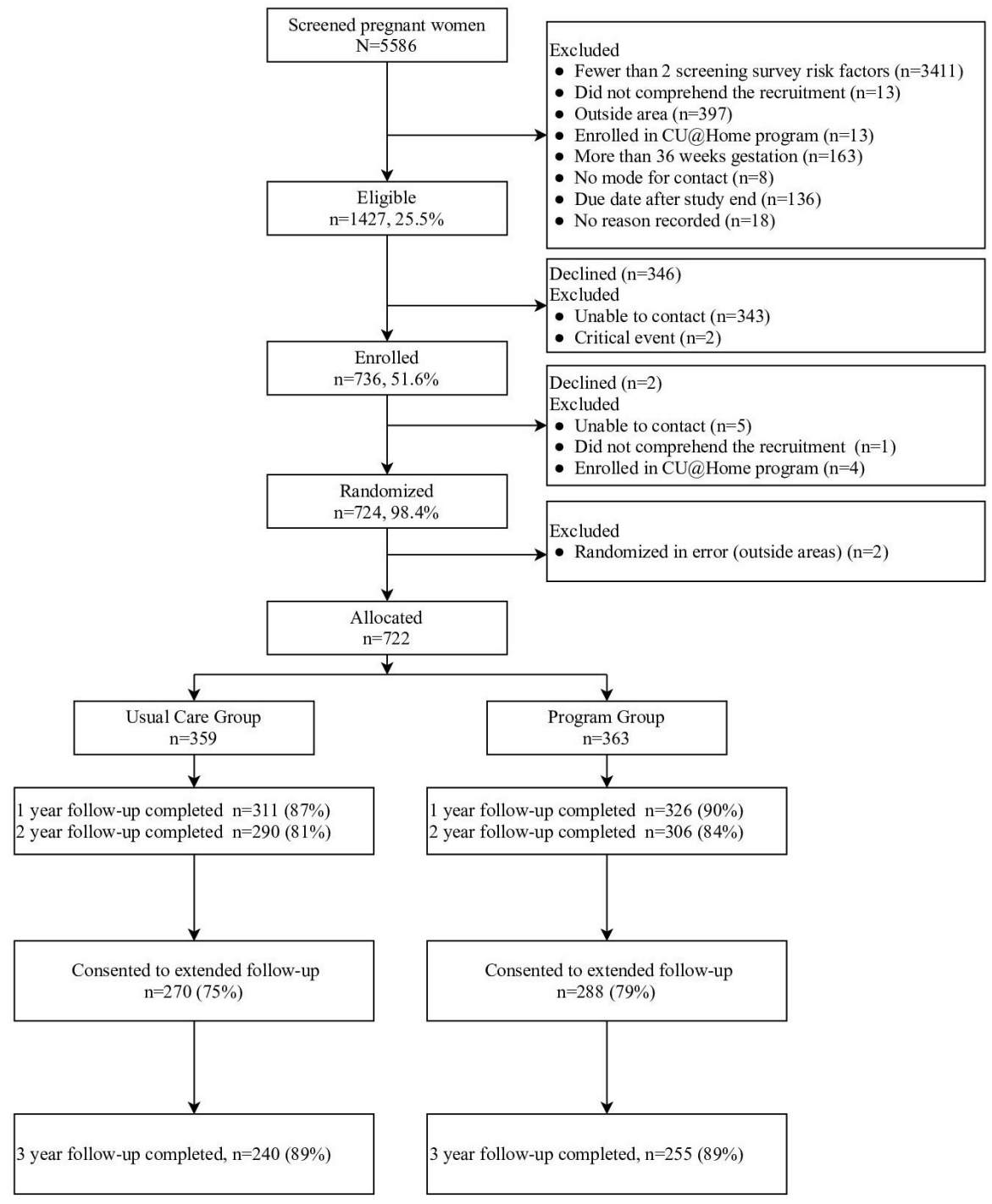

Figure 1 Participant flow chart.

(1000 simulations) and a cost effectiveness acceptability curve, which visually represents the probability that the intervention (compared with usual care) is cost-effective at varying threshold values of one QALY $(\$ A 0-\$ A 1.5 \mathrm{~m}) .{ }^{17}$

Analyses were conducted in Microsoft Excel and Stata V. $16 .^{24}$

\section{RESULTS}

\section{Participant characteristics}

At 3 years, 495 women ( $89 \%$ of $\mathrm{N}=558$ re-enrolled, $69 \%$ of original $\mathrm{N}=722$ ) (table 2 and figure 1 ) women provided data. More women were lost to follow-up who during pregnancy were younger, unemployed, reported high antenatal risk or poor mental health, or spoke a language other than English (table 2).

Health service use and cost

Compared with usual care, the NHV programme was associated with total increased costs over 3 years of $\$ A 7829$ (95\% CI $\$ A 4157$ to $\$ A 11501$ ) per family (table 3 ). This largely reflects the increased cost of nurse visits (primary health services category), due to increased number of visits received (see online supplemental table 2) and increased proportion of home visits. The mean cost of nurse visits to child age 3 years summed to $\$$ A6772 in the intervention group and \$A966 in the control group. Combined with social care practitioner visits and additional intervention costs, service costs were $\$ A 9415$ in right@home compared with \$A2162 in usual care, that is, an additional cost of $\$ A 7254$. As the intervention was delivered more intensively in the first year of child's life, the extra costs are largely accrued in the first year.

Other health service use varied, with no clear patterns across groups and no statistical evidence of differences at the aggregate level when combining all categories (except the above-mentioned primary health services) in any year or combining any category over 3 years. However, in the first year, the intervention group had higher use of hospital clinics and admissions than the usual care group. At the disaggregated level (online supplemental table 2), we can see that this is driven by a higher number of visits by both mothers and babies to hospital outpatient clinics, 
Table 3 Health service use and intervention costs (complete case analysis for discounted costs)

\begin{tabular}{|c|c|c|c|c|c|c|c|}
\hline \multirow{2}{*}{$\begin{array}{l}\text { All costs in \$A } \\
2016 / 2017\end{array}$} & \multicolumn{2}{|c|}{ Right@home n=363 } & \multicolumn{2}{|c|}{ Usual care $\mathrm{n}=359$} & \multirow{2}{*}{$\begin{array}{l}\text { Mean } \\
\text { difference }\end{array}$} & \multirow[b]{2}{*}{$P$ value } & \multirow[b]{2}{*}{$95 \% \mathrm{Cl}$} \\
\hline & $\mathbf{N}$ & Cost $^{\dagger}$ (mean (SD)) & $\mathbf{N}$ & Cost $^{\dagger}$ (mean (SD)) & & & \\
\hline \multicolumn{8}{|l|}{ Hospital clinics } \\
\hline Year 2 & 251 & 1026.20 (1639.31) & 226 & 1164.85 (2278.54) & -138.65 & 0.221 & -493 to 216 \\
\hline Year 3 & 198 & 1022.64 (2054.50) & 191 & 1046.28 (1842.15) & -23.64 & 0.453 & -413 to 365 \\
\hline Year 2 & 309 & 2680.74 (8428.60) & 290 & 2157.86 (5498.19) & 522.87 & 0.186 & -627 to 1673 \\
\hline Year 3 & 263 & 2294.75 (7173.01) & 247 & 2658.35 (7729.91) & -363.60 & 0.291 & -1660 to 933 \\
\hline \multicolumn{8}{|c|}{ Primary health services (includes NHV intervention) } \\
\hline Year 1 & 303 & $6987.26(2727.84)$ & 317 & $2687.93(1637.63)$ & 4299.33 & 0.000 & 3946 to 4652 \\
\hline Year 1 & 281 & $13144.14(20147.19)$ & 280 & $7861.09(12864.79)$ & 5283.05 & 0.000 & 2479 to 8088 \\
\hline Year 2 & 219 & $6564.58(9339.43)$ & 212 & $4922.15(7592.48)$ & 1642.43 & 0.023 & 28 to 3257 \\
\hline Year 3 & 189 & $3967.05(6981.44)$ & 179 & $4275.19(7935.25)$ & -308.15 & 0.346 & -1838 to 1223 \\
\hline \multicolumn{8}{|c|}{ Additional intervention costs* } \\
\hline Year 1 & 363 & $826.29(0.00)$ & 359 & $347.52(0.00)$ & 478.77 & - & - \\
\hline Year 2 & 363 & $382.15(0.00)$ & 359 & $347.52(0.00)$ & 34.63 & - & - \\
\hline \multicolumn{8}{|l|}{ Total cost } \\
\hline Year 1 & 281 & $13970.43(20147.0)$ & 280 & 8208.61 (12 864.79) & 5761.82 & 0.000 & 2957 to 8566 \\
\hline Year 2 & 219 & 6928.53 (9339.43) & 212 & $5253.12(7592.48)$ & 1675.41 & 0.021 & 61 to 3290 \\
\hline
\end{tabular}

*Training/material/supervision costs at the nurse level, in addition to the intervention costs included in primary health services.

†Unadjusted mean costs.

$\mathrm{NHV}$, nurse home visiting.

and higher emergency department visits in the child's first year, which is reversed in the second year.

\section{Health outcomes and cost-consequences analysis}

Table 4 shows that, compared with the usual care group, women in the intervention group reported improved mental health (Total Depression, Anxiety, Stress Scale score $\mathrm{ES}=0.18,95 \%$ CI 0.00 to 0.36 ) at child age 3 years. There was little evidence for group differences in child outcomes. The difficulty in comparing a substantial cost difference to a combination of ES across different outcome measures in cost-consequences analysis (table 4) is a reason to progress to the pre-specified secondary cost-utility analysis.

There was statistically significantly improved maternal QALYs in the third year (figure 2 and table 5) but no overall significant difference over the whole 3-year period (table 5).

\section{Incremental cost effectiveness ratio}

The ICER of the NHV intervention compared with usual care was estimated to be $\$ A 195675$ per QALY gained using complete case analysis and \$A258476 per QALY using multiply imputed data taking account of missing data and lost to follow-up. While all simulated cases demonstrated increased costs associated with the intervention, effects were far less certain (figure 3). The cost-effectiveness acceptability curve supports this, showing less than $20 \%$ probability of cost-effectiveness at a willingness-to-pay of $\$ A 50000$ per QALY at 3 years.

\section{DISCUSSION}

The economic evaluation confirms that the provision of a higher intensity and home-based nursing service in the right@home NHV programme resulted in substantially increased healthcare costs. We found limited group differences in all other health resource use and associated costs up to child age 3 years. There was evidence of benefits to maternal mental health at child age 3 years, which combined with benefits to parenting at 2 years, translate into marginal maternal QALY gains. At 12 months postintervention, the intervention is not cost-effective. 
Table 4 Cost-consequences analysis of right@home at 3 years against all health-related outcomes (using multiple imputation)

Descriptive statistics Comparative statistic: Intervention compared with control

\begin{tabular}{|c|c|c|c|c|c|c|c|}
\hline \multirow[b]{3}{*}{ Outcome } & \multicolumn{2}{|c|}{ Descriptive statistics } & \multicolumn{5}{|c|}{ Comparative statistic: Intervention compared with control } \\
\hline & \multirow{2}{*}{$\begin{array}{l}\text { Right@home (I) } \\
\text { Mean }\end{array}$} & \multirow{2}{*}{$\begin{array}{l}\text { Usual care (C) } \\
\text { Mean }\end{array}$} & \multicolumn{3}{|l|}{ Adjusted } & \multirow{2}{*}{$\begin{array}{l}\text { Effect } \\
\text { size }\end{array}$} & \multirow[b]{2}{*}{$95 \% \mathrm{Cl}$} \\
\hline & & & Mean difference & $95 \% \mathrm{Cl}$ & $P$ value & & \\
\hline Warm parenting & 4.63 & 4.64 & -0.02 & -0.13 to 0.08 & 0.622 & -0.05 & -0.26 to 0.17 \\
\hline Hostile parenting (reverse) & 7.94 & 7.76 & 0.18 & -0.16 to 0.52 & 0.259 & 0.10 & -0.09 to 0.29 \\
\hline Parenting efficacy & 8.07 & 7.91 & 0.16 & -0.15 to 0.48 & 0.284 & 0.10 & -0.09 to 0.28 \\
\hline Child-parent closeness & 32.28 & 32.33 & -0.10 & -0.73 to 0.53 & 0.739 & -0.03 & -0.21 to 0.15 \\
\hline \multicolumn{8}{|l|}{ Maternal health } \\
\hline $\begin{array}{l}\text { Mental health: DASS-overall } \\
\text { (Reverse scored) }\end{array}$ & 53.79 & 51.74 & 1.85 & 0.05 to 3.65 & 0.045 & 0.18 & 0.00 to 0.36 \\
\hline Quality of life: AQoL & 0.72 & 0.68 & 0.04 & -0.01 to 0.08 & 0.095 & 0.18 & -0.04 to 0.39 \\
\hline $\begin{array}{l}\text { Life satisfaction: Personal Well- } \\
\text { being Index }\end{array}$ & 58.95 & 56.23 & 2.37 & -0.59 to 5.34 & 0.103 & 0.17 & -0.04 to 0.37 \\
\hline \multicolumn{8}{|l|}{ Child language } \\
\hline $\begin{array}{l}\text { Receptive and expressive } \\
\text { language: CELF sentence } \\
\text { structure }\end{array}$ & 9.04 & 8.74 & 0.12 & -0.55 to 0.80 & 0.699 & 0.04 & -0.17 to 0.25 \\
\hline $\begin{array}{l}\text { Receptive and expressive } \\
\text { language: CELF word structure }\end{array}$ & 7.94 & 7.63 & 0.15 & -0.60 to 0.89 & 0.682 & 0.04 & -0.18 to 0.26 \\
\hline $\begin{array}{l}\text { Receptive and expressive } \\
\text { language: CELF expressive } \\
\text { vocabulary }\end{array}$ & 8.31 & 8.00 & 0.19 & -0.46 to 0.84 & 0.532 & 0.06 & -0.14 to 0.26 \\
\hline \multicolumn{8}{|l|}{ Child health } \\
\hline $\begin{array}{l}\text { Mental health and behaviour: } \\
\text { SDQ total behaviour problems } \\
\text { (reverse) }\end{array}$ & 27.66 & 27.19 & 0.25 & -0.87 to 1.36 & 0.639 & 0.04 & -0.14 to 0.22 \\
\hline $\begin{array}{l}\text { Quality of life: PedsQL physical } \\
\text { well-being }\end{array}$ & 90.99 & 89.42 & 1.51 & -1.17 to 4.18 & 0.244 & 0.12 & -0.09 to 0.32 \\
\hline $\begin{array}{l}\text { Quality of life: PedsQL } \\
\text { socioemotional well-being }\end{array}$ & 85.33 & 83.53 & 1.67 & -1.20 to 4.54 & 0.235 & 0.12 & -0.08 to 0.31 \\
\hline $\begin{array}{l}\text { Stress: child hair cortisol (pg/ } \\
\left.\text { mg, reverse log transformed }{ }^{*}\right)\end{array}$ & 1.93 & 1.69 & -0.24 & -0.54 to 0.06 & 0.106 & -0.21 & -0.47 to 0.06 \\
\hline \multicolumn{8}{|l|}{ Economic } \\
\hline Total costs $\$ A$ & 26192 & 18507 & 7685 & $7006 ; 8364$ & 0.000 & 0.28 & $0.26 ; 0.31$ \\
\hline
\end{tabular}

Adjusted for baseline characteristics of: child sex, family's Socio-Economic Index for Areas score, maternal education, maternal age at child's birth, parity, antenatal risk, maternal self-efficacy and maternal mental health; plus child age at the 3 years assessment.

*Natural log.

AQoL, assessment of quality of life; CELF, clinical evaluation of language fundamentals ; CPRS, Child Parent Relationship Scale; DASS, Depression, Anxiety, Stress Scale; PedsQL, paediatric quality of life inventory; SDQ, Strengths and Difficulties Questionnaire.

The implementation costs of the right@home NHV programme (\$A7254) are similar to the range of costs reported for NHV programmes in other high-income countries. The NFP estimated programme costs of US $\$ 12265^{12}$ (\$A17503 in $2016 / 2017$ prices), ${ }^{25} 26$ the Building Blocks programme (based on NFP) in England 


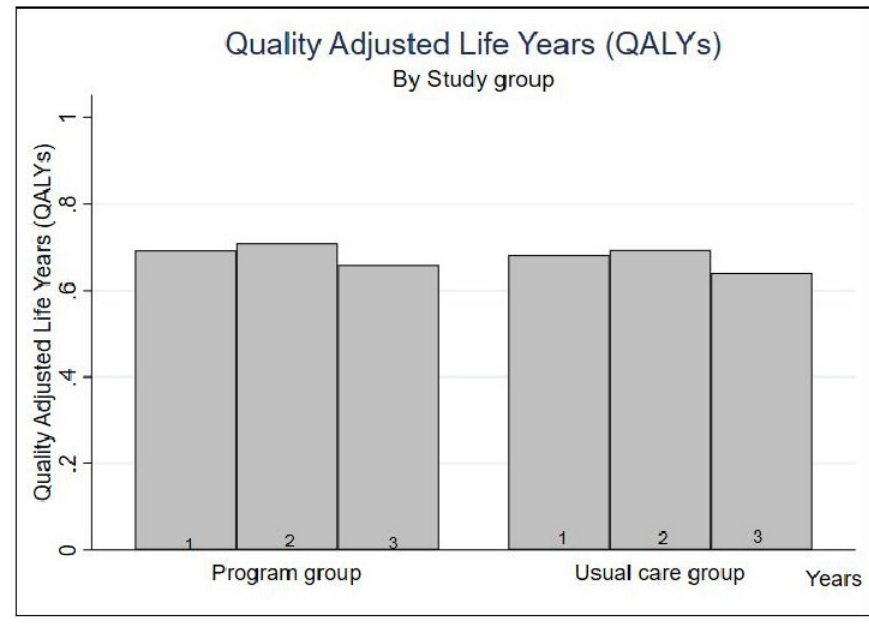

Figure 2 QALYs over 3 years, using imputed data.

estimated additional costs of GBP1812 (\$A4166) ${ }^{4}$ and an earlier NHV programme in England estimated additional costs of GBP3246 (\$A9523). ${ }^{27}$ Two previous studies have assessed the impact of NHV programmes on QALYs. A 2011 economic evaluation of the Denver NFP to child age 9 years estimated 0.15 additional QALYs accrued to mother/child dyad over the 9-year period, largely from reduced maternal depression. ${ }^{9} 28$ An economic evaluation of the UK's family nurse partnership programme (Building Blocks) to child age 2 found 0.0036 additional QALYs per mother $(95 \% \mathrm{CI}-0.017$ to 0.025$) .{ }^{4}$ In comparison, we find 0.01 additional QALYs per mother (95\% CI -0.01 to 0.02 ) to child age 3 .

Economic evaluations of NHV programmes assess whether the benefits generated by the programme represent value for money in comparison to the programme costs. In the US healthcare system, the NFP programme has generated increasing health and economic benefits over time. Cost savings to government are estimated to outweigh upfront programme costs between child age 9 and 30, depending on the effectiveness estimates used in analysis. ${ }^{9} 1229$ This means that decision making on NHV programmes should consider costs and outcomes over a sufficiently long time period, despite the inherent conflict between policy/decision timing and availability of follow-up data. While the right@home NHV programme is not cost-effective at 12 months post-intervention, costeffectiveness may improve over time if benefits continue to accrue to mothers and/or children; ongoing follow-up of right@home will collect cost and outcome data up to school age.

Applications of NHV programmes in high-income countries have sought to address whether the positive results in the US context can be replicated when NHV is added to an existing universal healthcare system. In Australia, for example, 'usual care' represents a higher level of $\mathrm{CFH}$ service delivery compared with the US context. The concept that NHV offers a small change from existing service delivery is posited as an explanation for lack of positive outcomes for trials of NHV in England. ${ }^{4}$ For the right@home NHV programme at child age 3years, the economic evaluation demonstrates increased costs and only limited benefits; however, these findings may change at older ages in line with previous studies and the general early intervention literature where benefits emerge as children age and enter adulthood with benefit lags up to 30 years post-intervention. ${ }^{12}$

Broader health service use costs were slightly higher for right@home compared with usual care in the first year, with some reversal in later years. The increased professional contact of the NHV programme may directly identify health concerns, or improve predisposing individual factors like knowledge and awareness to prompt women to use healthcare services more often. ${ }^{30}$ This should be interpreted as a positive outcome, as increasing women's connection to and use of appropriate services is an objective of this and other NHV programmes. Although any increased use of services will have additional costs to government providers, if this is filling or narrowing a gap in appropriate care, it may well lead to concomitant or future improvements in health outcomes.

Strengths of the trial include the rigorous design and outcome assessments completed by researchers who were blinded to intervention status. The research retained a high proportion of study participants in both groups $(69 \%$ over a 4 -year study duration), despite the substantial adversity experienced by participants. For context, by the 2-year follow-up, the Building Blocks study retained $71 \%$ of their cohort for self-reported

Table 5 Quality-adjusted life-years (QALYs) (using multiple imputation)

\begin{tabular}{|c|c|c|c|c|c|c|c|}
\hline \multirow[b]{3}{*}{ Outcome } & \multicolumn{2}{|c|}{ Descriptive statistics QALYs } & \multicolumn{5}{|c|}{ Comparative statistic: intervention compared with control } \\
\hline & \multirow{2}{*}{$\begin{array}{l}\text { Right@home (I) } \\
\text { Mean }\end{array}$} & \multirow{2}{*}{$\begin{array}{l}\text { Usual care (C) } \\
\text { Mean }\end{array}$} & \multicolumn{3}{|c|}{ Adjusted* } & \multirow[b]{2}{*}{ Effect size } & \multirow[b]{2}{*}{$95 \% \mathrm{Cl}$} \\
\hline & & & Mean difference & $95 \% \mathrm{Cl}$ & $P$ value & & \\
\hline Year 2 & $0.69(0.17)$ & $0.69(0.15)$ & 0.00 & -0.01 to 0.01 & 0.12 & -0.02 & -0.04 to 0.01 \\
\hline Year 3 & $0.65(0.16)$ & $0.64(0.16)$ & 0.01 & -0.00 to 0.01 & 0.00 & 0.05 & 0.03 to 0.08 \\
\hline
\end{tabular}

*Adjusted for baseline characteristics of: quality of life, child sex, family's Socio-Economic Index for Areas score, maternal education, maternal age at child's birth, parity, antenatal risk, maternal self-efficacy and maternal mental health; plus child age at the 3-year assessment. 

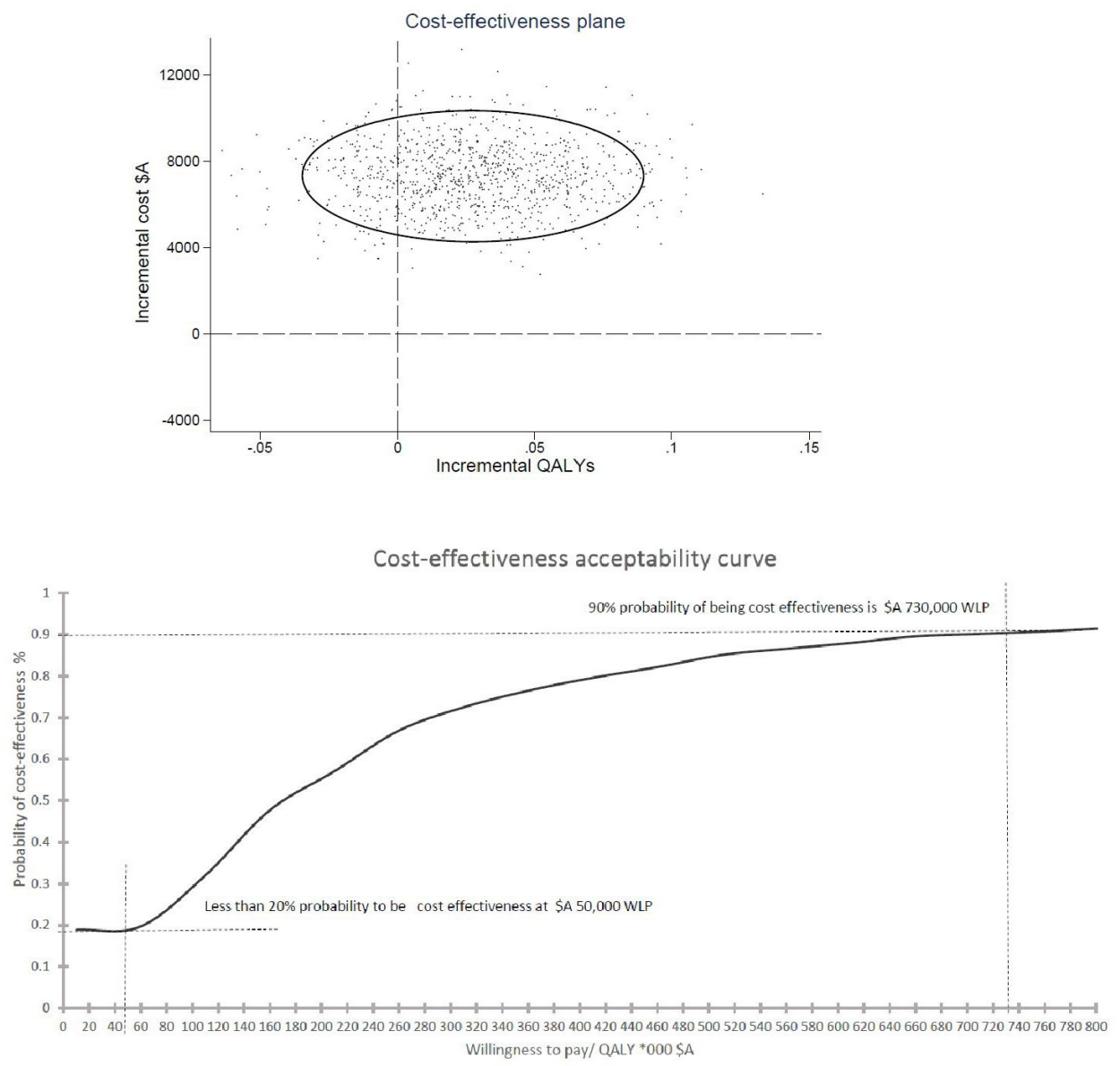

Figure 3 Cost-effectiveness plane and cost-effectiveness acceptability curve. QALYs, quality-adjusted life-years.

outcomes $^{31}$ and other European studies retained less than $50 \% .^{62}$ Given the large, multisite design of the trial, high participant retention and use of multiple imputation to address missing data arising from participant attrition, we believe our findings should generalise to pregnant women experiencing adversity, in similar healthcare systems.

There are several limitations. Maternal report was used to measure broader health service use and quality of life outcomes and responses may be subject to perception influenced by participation in the intervention. There is a possibility of recall bias when answering service use questions over a 6-month recall period, although any bias should be distributed equally across trial arms. ${ }^{33}$ Quality of life data for children were not included in QALY measures. Service use data excludes the use and costs of other government services such as child protection and associated legal services, as these data were not collected in this period of the trial. Women were more likely to be lost to follow-up if they were younger, unemployed or reported higher antenatal risk; despite multiple imputation of outcome data, the cost and cost-effectiveness results may not fully represent these women. In addition, trial exclusion criteria meant that findings may not generalise to non-English speaking women or women with severe intellectual disability.

\section{CONCLUSION}

The embedding of an NHV programme into the Australian universal health system demonstrates benefits to parenting and the home environment when the intervention ends at child age 2 years, ${ }^{18}$ and improves maternal mental health 12 months later. As expected, implementing an NHV programme requires substantial up-front investment. Economic evaluation based on the outcomes evident by child age 3 years shows a lack of cost-effectiveness, due to a lack of short term cost-savings and only marginal maternal QALY gain. Ongoing follow-up will assess whether continued accrual of benefits to mothers and children outweigh the increased up-front costs as shown in other NHV programs over a longer period of time.

Author affiliations

${ }^{1}$ School of Health and Social Development, Deakin University, Burwood, VIC, 3125, Australia

${ }^{2}$ Population Health, Murdoch Children's Research Institute, Parkville, VIC, 3052, Australia

${ }^{3}$ Centre for Community Child Health, The Royal Children's Hospital, Parkville, VIC, 3052, Australia

${ }^{4}$ Department of Paediatrics, The University of Melbourne, Parkville, VIC, 3052, Australia

${ }^{5}$ Clinical Epidemiology and Biostatistics Unit, Murdoch Children's Research Institute, The Royal Children's Hospital, Melbourne, VIC, 3052, Australia

${ }^{6}$ Melbourne Children's Trials Centre, Murdoch Children's Research Institute, The Royal Children's Hospital, Parkville, VIC, 3052, Australia 
${ }^{7}$ Australian Research Alliance for Children and Youth, Canberra City, ACT, 2601, Australia

${ }^{8}$ Ingham Institute, Western Sydney University, Penrith, NSW, 2751, Australia

Twitter Anna M H Price @amhprice, Hannah E Bryson @HannahEBryson, Harriet Hiscock @harrietHiscock and Tracey Bruce @TracybruceBruce

Acknowledgements The 'right@home' sustained nurse home visiting trial is a research collaboration between the Australian Research Alliance for Children and Youth (ARACY); the Translational Research and Social Innovation (TReSI) Group at Western Sydney University; and the Centre for Community Child Health (CCCH), which is a department of The Royal Children's Hospital and a research group of Murdoch Children's Research Institute. We thank all families, the researchers, nurses and social care practitioners working on the right@home trial, the antenatal clinic staff at participating hospitals who helped facilitate the research, and the Expert Reference Group for their guidance in designing the trial.

Contributors SBM and LG conceptualised and conducted the economic evaluation. SG, LK, AMHP, FKM, HEB, SP, FO, PD, TB, DH, KN and HH conceptualised the study design, provided statistical expertise, contributed to the first draft and subsequent revisions of the manuscript. SBM and LG are responsible for the overall content as the guarantor. All authors approved the final manuscript as submitted and agree to be accountable for all aspects of the work.

Funding This work is supported by the state governments of Victoria and Tasmania, the lan Potter Foundation, Sabemo Trust, Sidney Myer fund, the Vincent Fairfax Family Foundation, and the National Health and Medical Research Council (NHMRC, 1079418). The MCRI administered the research grant for the study and provided infrastructural support to its staff but played no role in the conduct or analysis of the trial. Research at the MCRI is supported by the Victorian Government's Operational Infrastructure Support Program. SG was supported by NHMRC Practitioner Fellowship (1155290). FKM was supported by NHMRC Career Development Fellowship (1111160). HH was supported by NHMRC Practitioner Fellowship (1136222)

Disclaimer The funding bodies had no role in relation to the design and conduct of the study; collection, management, analysis, and interpretation of the data; preparation, review, or approval of the manuscript; and decision to submit the manuscript for publication.

Competing interests The 'right@home' sustained nurse home visiting trial is a research collaboration between the Australian Research Alliance for Children and Youth (ARACY); the Translational Research and Social Innovation (TReSI) Group at Western Sydney University; and the Centre for Community Child Health (CCCH), which is a department of The Royal Children's Hospital and a research group of Murdoch Children's Research Institute. Ownership of the right@home implementation and support licence, which is purchased by Australian state governments for roll out, is shared between institutes.

Patient consent for publication Not applicable.

Ethics approval The ethics committees of the Royal Children's Hospital (HREC 32296); Deakin University (HREC 2013/147); Peninsula Health (HREC/13/PH/14); Ballarat Health Services (HREC/13/BHSSJOG/9); Southern Health (HREC 13 084X); Northern Health (HREC P03/13) (all Victoria), and the University of Tasmania (HREC H0013113) approved this study.

Provenance and peer review Not commissioned; externally peer reviewed.

Data availability statement Data are available on reasonable request. We invite researchers to request access to the data from the Melbourne Children's Campus LifeCourse institutional data access platform (https://lifecourse.melbournechildrens com/data-access/) or the governing Royal Children's Hospital HREC (https://www. rch.org.au/ethics/).

Supplemental material This content has been supplied by the author(s). It has not been vetted by BMJ Publishing Group Limited (BMJ) and may not have been peer-reviewed. Any opinions or recommendations discussed are solely those of the author(s) and are not endorsed by BMJ. BMJ disclaims all liability and responsibility arising from any reliance placed on the content. Where the content includes any translated material, BMJ does not warrant the accuracy and reliability of the translations (including but not limited to local regulations, clinical guidelines, terminology, drug names and drug dosages), and is not responsible for any error and/or omissions arising from translation and adaptation or otherwise.

Open access This is an open access article distributed in accordance with the Creative Commons Attribution Non Commercial (CC BY-NC 4.0) license, which permits others to distribute, remix, adapt, build upon this work non-commercially, and license their derivative works on different terms, provided the original work is properly cited, appropriate credit is given, any changes made indicated, and the use is non-commercial. See: http://creativecommons.org/licenses/by-nc/4.0/.

\section{ORCID iDs}

Shalika Bohingamu Mudiyanselage http://orcid.org/0000-0003-1090-4401

Anna M H Price http://orcid.org/0000-0002-8117-8059

Fiona K Mensah http://orcid.org/0000-0002-6951-9949

Hannah E Bryson http://orcid.org/0000-0002-3294-620X

Susan Perlen http://orcid.org/0000-0001-7814-9743

Francesca Orsini http://orcid.org/0000-0001-5183-5946

Harriet Hiscock http://orcid.org/0000-0003-3017-2770

Diana Harris http://orcid.org/0000-0001-5282-9521

Tracey Bruce http://orcid.org/0000-0003-0546-5547

Sharon Goldfeld http://orcid.org/0000-0001-6520-7094

Lisa Gold http://orcid.org/0000-0002-2733-900X

\section{REFERENCES}

1 Olds DL. The nurse-family partnership: an evidence-based preventive intervention. Infant Ment Health J 2006;27:5-25.

2 United States of America and Department of Health and Human Services (DHHS). Home visiting evidence of effectiveness (HomVEE), 2019. Available: https://homvee.acf.hhs.gov/ [Accessed 6 May 2019]

3 Goldfeld S, Price A, Kemp L. Designing, testing, and implementing a sustainable nurse home visiting program: Right@home. Malden, Massachusetts: Blackwell Publishing Inc, 2018.

4 Corbacho B, Bell K, Stamuli E, et al. Cost-Effectiveness of the family nurse partnership (FNP) programme in England: evidence from the building blocks trial. J Eval Clin Pract 2017;23:1367.

5 Jack SM, Catherine N, Gonzalez A, et al. Adapting, piloting and evaluating complex public health interventions: lessons learned from the Nurse-Family partnership in Canadian public health settings. Health Promot Chronic Dis Prev Can 2015;35:151-9.

6 Sierau S, Dähne V, Brand T, et al. Effects of home visitation on maternal competencies, family environment, and child development: a randomized controlled trial. Prev Sci 2016;17:40-51.

7 Zarnowiecki D, Nguyen $\mathrm{H}$, Catherine H. The Australian Nurse-Family partnership program for Aboriginal mothers and babies: describing client complexity and implications for program delivery. Midwifery 2018;65:72-81

8 Mejdoubi J, van den Heijkant SCCM, van Leerdam FJM, et al. The effect of VoorZorg, the Dutch nurse-family partnership, on child maltreatment and development: a randomized controlled trial. PLoS One 2015;10:e0120182-e82.

9 Stamuli E, Richardson G, Duffy S, et al. Systematic review of the economic evidence on home visitation programmes for vulnerable pregnant women. Br Med Bull 2015;115:19-44.

10 Olds DL, Henderson CR, Phelps C, et al. Effect of prenatal and infancy nurse home visitation on government spending. Med Care 1993;31:155-74.

11 O'Dwyer L. A critical review of evidence-based policy making, Australian housing and urban research Institute final report No. 58. Melbourne: Australian Housing and Urban Research Institute Limited, 2004. https://www.ahuri.edu.au/research/final-reports/58

12 Washington State Institute for Public Policy (WSIPP). Nurse family partnership Washington, United States 2019 [updated Benefit-cost methods last updated December 2019, 2018. Available: http://www. wsipp.wa.gov/benefitcost/program/35

13 Cannon JS KM, Karoly LA, Matox T. Investing early: taking stock of outcomes and economic returns from early childhood programs. Rand Health Quaeterly 2017;7:6.

14 Goldfeld S, Price A, Bryson H, et al. 'right@home': a randomised controlled trial of sustained nurse home visiting from pregnancy to child age 2 years, versus usual care, to improve parent care, parent responsivity and the home learning environment at 2 years. BMJ Open 2017;7:e013307.

15 Department of Health and Human Services. Maternal and child health service framework state of Victoria. Australia: Victorian Government, 2019. https://www.health.vic.gov.au/maternal-child-health/maternaland-child-health-service-framework

16 Coast J. Is economic evaluation in touch with Society's health values? BMJ 2004;329:1233-6.

17 George B, Harris A, Mitchell A. Cost-Effectiveness analysis and the consistency of decision making. Pharmacoeconomics 2001;19:1103-9.

18 Goldfeld S, Price A, Smith C, Bryson H, et al. Nurse home visiting for families experiencing adversity: a randomized trial. Pediatrics $2019 ; 143$ 
19 Maxwell A, Özmen M, lezzi A, et al. Deriving population norms for the AQoL-6D and AQoL-8D multi-attribute utility instruments from webbased data. Qual Life Res 2016;25:3209-19.

20 Independent Hospital Pricing Authority (IHPA). National weighted activity unit (NWAU) Australia, 2016. Available: https://www.ihpa.gov. au/what-we-do/national-weighted-activity-unit-nwau-calculators2015-16

21 The Centre for Health Economics Research and Evaluations (CHERE). Discounting in economic evaluations in health care: a brief review: cancer research economics support team, 2019. Available: https://www.uts.edu.au/sites/default/files/2019-04/crest-factsheetdiscounting.pdf

22 Attema AE, Brouwer WBF, Claxton K. Discounting in economic evaluations. Pharmacoeconomics 2018;36:745-58.

23 Edney LC, Haji Ali Afzali $\mathrm{H}$, Cheng TC, et al. Estimating the reference incremental cost-effectiveness ratio for the Australian health system. Pharmacoeconomics 2018;36:239-52.

24 StataCorp. Stata statistical software. College Station, TX: StataCorp LLC, 2019. https://www.stata.com/order/

25 Australian Bureau of Statistics. Consumer price index, Australia, 2020. Available: https://www.abs.gov.au/statistics/economy/priceindexes-and-inflation/consumer-price-index-australia/latest-release

26 The Organisation for Economic Co-operation and Development (OECD). Purchasing power parities (PPP), 2020. Available: https:// data.oecd.org/conversion/purchasing-power-parities-ppp.htm

27 Mclntosh E, Barlow J, Davis $\mathrm{H}$, et al. Economic evaluation of an intensive home visiting programme for vulnerable families: a costeffectiveness analysis of a public health intervention. J Public Health 2009;31:423-33.

28 Australin Government Department of Health. MBS online: medicare benefits schedule: item 296. Canberra, ACT: Commonwealth of Australia, 2017. http://www9.health.gov.au/mbs/fullDisplay.cfm? type=item\&qt=ItemID\&q=296

29 Olds D, Miller TR, Knudtson M. Impact of the nurse-family partnership on neighborhood context, government expenditures, and children's school functioning. Rockville, Maryland, USA: National Criminal Justice Reference Service, 2011.

30 Andersen RM, Ronald MA. Revisiting the behavioral model and access to medical care: does it matter? J Health Soc Behav 1995;36:1.

31 Robling M, Bekkers M-J, Bell K, et al. Effectiveness of a nurse-led intensive home-visitation programme for first-time teenage mothers (building blocks): a pragmatic randomised controlled trial. Lancet 2016;387:146-55.

32 Foulon S, Greacen T, Pasquet B, et al. Predictors of study attrition in a randomized controlled trial evaluating a perinatal Home-Visiting program with mothers with psychosocial vulnerabilities. PLoS One 2015;10:e0142495.
33 Dalziel K, Li J, Scott A, et al. Accuracy of patient recall for selfreported doctor visits: is shorter recall better? Health Econ 2018;27:1684-98.

34 Independent Hospital Pricing Authority (IHPA). National Hospital cost data collection, public hospitals cost report, round 19 Australia, 2016. Available: https://www.ihpa.gov.au/publications/nationalhospital-cost-data-collection-public-hospitals-cost-report-round-19financial

35 Australian Government Department of Health. MBS online: medicare benefits schedule: item 82140. Canberra, ACT: Commonwealth of Australia, 2017. http://www9.health.gov.au/mbs/search.cfm?q= 82140\&Submit=\&sopt=S

36 Australian Psychology Association. APS national schedule of recommended fees (not including G.S.T.) and item numbers* for psychological services Australia, 2017. Available: https:// www.psychology.org.au/getmedia/af30b47d-ef39-49c2-81166d20ed1dc828/18APS-2018-19-APS-IS-SRF-P1-a.pdf

37 Australian Government Department of Health. MBS online: medicare benefits schedule: item 80160. Canberra, ACT: Canberra, ACT, Commonwealth of Australia, 2017. http://www9.health.gov.au/mbs/ fullDisplay.cfm?type=item\&qt=ItemID\&q=80160

38 Australian Government Fair Work Ombudsman. Pay guide - nurses award - 2010. Pay guide - nurses award Australia 2017;MA000034 https://www.fairwork.gov.au/pay-and-wages/minimum-wages/payguides

39 Australin Government Department of Health. MBS online: medicare benefits schedule: item 023. Canberra, ACT: Commonwealth of Australia, 2017. http://www9.health.gov.au/mbs/search.cfm?q=023\& Submit=\&sopt $=$ S

40 Australian Government Department of Health. MBS online: medicare benefits schedule: item 10968. Canberra, ACT: Commonwealth of Australia, 2017. http://www9.health.gov.au/mbs/search.cfm?q= 10968\&Submit=\&sopt $=S$

41 Australian Government Department of Health. MBS online: medicare benefits schedule: item 135. Canberra, ACT: Commonwealth of Australia, 2017. http://www9.health.gov.au/mbs/fullDisplay.cfm? type=item\&qt=ItemID\&q=135

42 Australian Government Department of Health. MBS online: medicare benefits schedule: item 132. Canberra, ACT: Commonwealth of Australia, 2017. http://www9.health.gov.au/mbs/fullDisplay.cfm? type=item\&qt=ItemID\&q=132

43 Australian Government Department of Health. MBS online: Medicare benefits schedule: allied health services. Canberra, ACT: Commonwealth of Australia, 2018: 1173-84.

44 Australian Government Department of Veterans Affairs. Fee schedule of dental services for dentists and dental specialists. Australia 2014 https://www.dva.gov.au/providers/notes-fee-schedules-andguidelines/fee-schedules/dental-and-allied-health-fee-schedules 